\title{
Proposal of a protocol of rehabilitation and photomodulation laser in the treatment of patients in the post-surgical of partial meniscectomy
}

\author{
Vivian C Junglos ${ }^{1}$, Marcia MG Costa ${ }^{1}$, Rafael I Barbosa ${ }^{1,2}$, Heloyse U Kuriki ${ }^{1,2}$, Lais MS das Neves ${ }^{1}$, Alexandre M Marcolino ${ }^{1,2 *}$ and Marisa $^{2}$ \\ de Cássia R Fonseca ${ }^{3}$ \\ ${ }^{1}$ Department of Health Sciences, Universidade Federal de Santa Catarina, Brazil. \\ ${ }^{2}$ Postgraduate Program in Rehabilitation Sciences, Federal University of Santa Catarina, Brazil. \\ ${ }^{3}$ Postgraduate Program in Rehabilitation and Functional Performance, University of São Paulo, Brazil
}

\begin{abstract}
Meniscus are important structures for knee biomechanics, have primary functions in weight loss, increased joint congruence and influence in nutrition and lubrication of articular cartilage, meniscal lesions comprise $12-14 \%$ of the lesions that affect the knee joint. The objective of this study is to evaluate the influence of the photobiomodulation laser associated rehabilitation protocol in the treatment of patients in the postoperative period of partial meniscectomy. Two post-operative meniscal lesions participated in the study, one of which ended the treatment, one gave up of the treatment. The patient were submitted to a functional evaluation through questionnaires and functional test $Y$ balance test, maximum isometric muscle strength test, pain evaluation and electromyographic evaluation of the quadriceps and hamstring muscles. Evaluations were performed at the beginning and at the end of treatment. The treatment consists of an exercise protocol associated with or not laser photobiomodulation. The participant who completed the protocol was female, aged 51 years, and the affected knee being the right. Patient received the treatment protocol associated with laser photobiomodulation $830 \mathrm{~nm}$. An evaluation performed before and after the treatment protocol demonstrates improvement in range of motion, change the parameter of te electromyography, reduction of edema, increase in pain threshold, and improvement in functionality. This treatment protocol in the case report proved to be adequate and effective for the post-operative meniscectomy, providing an effective management of partial meniscectomy in patient assessment before and after treatment protocol.
\end{abstract}

\section{Introduction}

The knee joint is a complex segment, having in particular the meniscus that are fibrocartilaginous structures located between the femoral and tibial condyles. The menisci are essential structures for the various functions of the knee in activities of daily living, leisure and sports activities. The main functions are: distributing stress through the knee during weight bearing by performing load transmission at the joint, providing impact absorption, increasing joint congruence, providing nutrition and lubrication of joint cartilage, and preventing knee hyperextension [1-3].

The review written by Brindle et al. [1], pointed out that meniscal injuries accounted for $12 \%$ of all knee injuries. A survey of knee injuries at the National Association of Athletic Trainers has projected that approximately 9000 knee surgeries are performed annually in these athletes.

Frizziero et al. [4] studying the epidemiology of knee injuries found an incidence of $12-14 \%$ and a prevalence of 61 cases per 100,000 people of meniscal injuries, being the second most common cause among knee injuries. In an epidemiological study conducted on 17,397 patients in Germany and Switzerland, soccer, followed by skiing, are sports that offer the greatest risk of meniscal injury. Among the lesions that affect the knee, it shows that most involve Anterior Cruciate Ligament (ACL) (20.34\%), medial meniscus (10.76\%) and lateral meniscus (3.66\%). $\mathrm{He}$ also notes that $85 \%$ of patients with meniscal lesions require and require arthroscopic treatment.
Due to the high number of lesions, it is necessary the importance of well-defined treatments and appropriate to the type of injury. Current evidence suggests that although non-surgical management may be beneficial, about one-third of patients will undergo a surgical procedure followed by rehabilitation to achieve satisfactory relief of pain and functional outcomes [3].

Brelin and Rue [5] pointed out the existence of a global incidence of meniscal injuries requiring surgery from 60 to 70 per 100,000 people per year and about one third of these injuries are sport related.

Among the most commonly used surgeries, total meniscectomy was initially the procedure of first choice of surgeons. Due to the early onset of osteoarthritis, the professionals explored other surgical options. A partial meniscectomy has since replaced total meniscectomy, such as surgery of choice, along with other options such as repairs and transplants. The meniscal repair is divided into two main types, the open repair being less common, due to the greater tissue trauma associated with larger surgical incisions, although good results have been reported.

${ }^{\star}$ Correspondence to: Alexandre Marcio Marcolino, Federal University of Santa Catarina / UFSC - Physiotherapy, LARAL - Locomotor Evaluation and Rehabilitation Laboratory, Rua Pedro João Pereira, 150, CEP: 88905-120 Araranguá - SC, Campus Mato Alto, Brazil, E-mail: alexandre.marcolino@ufsc.br

Key words: laser therapy; exercise therapy; meniscectomy

Received: May 31, 2019; Accepted: June 15, 2019; Published: June 20, 2019 
The arthroscopic repair with benefits of smaller incisions and a reduced risk of neurovascular injury [1].

Nakamura et al. [6] highlights the effectiveness of the low-intensity laser in relieving chronic pain in the knee joint caused by meniscal injury and osteoarthritis. Treatment continued to irradiate four points per session, twice a week for four weeks, achieving a good and excellent improvement respectively in 21 of the 35 treated patients. Frizziero et al. [4] reports the effectiveness of rehabilitation protocols in different surgical procedures in improving pain, movement, quadriceps strength and return to daily life activities, however, concludes by highlighting the lack of details in describing the protocols so that their possible.

\section{Methods}

\section{Study design}

This research is characterized by being a longitudinal, prospective study of clinical evaluation and intervention, in which the comparison of the influence of a rehabilitation protocol associated or not with the photobiomodulation laser $(660 \mathrm{~nm}$ and $810 \mathrm{~nm}$ ) will be analyzed, observing the function, muscle strength, activation, and the rate of firing of motor units of the lower limb muscles in post-surgical patients with partial meniscectomy.

The collections took place in the second semester of 2017 and in the first half of 2018 at the Laboratory of Evaluation and Rehabilitation of the Locomotive Apparatus - LARAL of the Federal University of Santa Catarina - UFSC Campus Araranguá - SC. Participants were patients with partial meniscectomy post-operative. Inclusion criteria were individuals in the postoperative period of partial meniscectomy of the lateral or medial meniscus, aged between 18 and 60 years. Those who presented rheumatic, systemic, cognitive and polytraumatized patients that made the execution of the project impossible were excluded.

Each individual was evaluated from the International Physical Activity Questionnaire (IPAQ), which allows us to estimate the weekly time spent in moderate and vigorous physical activity in different situations of daily life such as work, transportation, domestic activities and leisure, and also time in passive activities performed in the sitting position. The short version of the IPAQ consists of seven open-ended questions that estimate the time spent per week in different dimensions of physical activity such as walking and physical exertion of moderate and vigorous intensities and physical inactivity in the seated position [7].

The Westerm Ontario and McMaster Universities (WOMAC) questionnaire, which allows the collection of information about the patients' perception of their health status and usually consists of the assessment of the different dimensions of the health status of patients with osteoarthritis, can be used to evaluate both patients with hip and knee osteoarthritis and is validated for the Brazilian population [8].

The Lysholm Knee Scoring Scale (LYSHOLM) questionnaire was applied for the functional evaluation of patients with knee symptomatology most used in the area of traumatology [9].

For the evaluation of the pressure pain threshold, we used the algometro, which was applied to the articular line of the meniscal compartment affected by the surgical procedure $[10,11]$.

The assessment of range of motion was measured by goniometry. It is very useful for measuring and recording deficits due to deformities, immobility or joint fractures and presents a satisfactory level of reliability.
The gait assessment can detect the presence of abnormal movement of the patella, and of the tibia in relation to the femur, and may indicate possible problems of instability. It is important to observe the proximal segments as well, because the weakness of hip abductors causes increased stress on the knee joint. The gait analysis was performed using Kinovea software, which performs a two-dimensional analysis of joint positioning in the gait phase evaluated.

The muscle strength evaluation was performed by the Hand-held dynamometer, the muscle groups evaluated were the medial and lateral rotators of the hip, and the knee flexors and extensors. The step up test was also performed, which evaluates the involvement of the patellofemoral joint that may cause disability due to being associated with meniscal lesions [12].

For the application of the CORE muscle strength test, the orientation was that the volunteer remain in lateral decubitus under a mat, with maintenance of the support on his elbow and his feet or knees, without touching the pelvis to the ground. In addition, the upper leg remained in front of the lower leg with both feet to the ground, the upper arm remained on the trunk with the hand pointed to the feet and the pelvis was raised from the ground and maintained in a straight line as an axis to the body between the feet (knees) and the elbow. The test was completed when the volunteer was not able to maintain the instructed position, recording the maximum tolerated time $[13,14]$.

The functional evaluation of the lower limbs of the volunteers was performed through the Y balance test, according to Stiffler et al. [15]. The maneuvers to perform the Y Balance Test were performed in unipodal support directing the contralateral lower limb in the anterior (ANT), posteromedial (PM) and posterolateral (PL) directions using the hallux to touch the ground during the execution of the movement. All participants performed three tasks in each learning direction with the lower limb not affected. The length of both lower limbs was measured from the anatomical points of the antero-superior iliac crest to the distal tip of the medial malleolus. The test was performed three times in each direction with both lower limbs, recording the maximum distance in centimeters of reach in each direction. The Y balance test score was determined by the sum of the mean distance distances of the affected and non-affected limb in each direction, dividing by three times the leg length, and multiplying by 100 to obtain the percentage, the test was performed with the patient barefoot [16-18].

The electromyographic analysis will be used to evaluate the recruitment pattern of the hamstrings and quadriceps muscles bilaterally electrode positioning are recommended by SENIAM (surface electromyography for non-invasive assessment of muscles). through the Miotec ${ }^{\oplus}$ electromyograph (Miotool 400, Software Miograph ${ }^{\circ}$ ), with an analog to digital (A / D) converter of 14 bits resolution, acquisition amplified at $2000 \mathrm{~Hz}$ and common rejection mode of $100 \mathrm{~dB}$, with bandpass filter of 10-500 Hz.

The electrodes will be of the Double type disposable type, made of polyethylene foam with hypoallergic medical adhesive, solid adherent gel, $\mathrm{Ag} / \mathrm{AgCl}$ bipolar contact (silver / silver chloride) and $20 \mathrm{~mm}$ distance between the poles, to decrease the electrical impedance of the patients' skin will be prepared to place the surface electrodes on the skin for posterior capture of the EMG signals. The preparation included removal of hair with the aid of a disposable razor and a light exfoliation of the skin performed with the friction of dermatological sandpaper and then cotton moistened with $70 \%$ alcohol in place. The skin preparation was recommended by SENIAM (surface electromyography for non-invasive assessment of muscles). The acquisition of the 
electromyographic signals will be by the maximum voluntary isometric contraction of each muscle, and the activation (Root Mean Square RMS) and rate of firing the motors units (Median Frequency - Fmed) of each muscle will be evaluated [19].

\section{Treatment protocol}

\section{Rehabilitation protocol}

Participants in this group will receive treatment through the rehab protocol for 12 weeks, with two weekly sessions and a 48-hour interval between sessions.

Rehabilitation protocol associated with laser photobiomodulation $(660 \mathrm{~nm})$ irradiation: Participants in this group will receive treatment through the laser photobiomodulation $(660 \mathrm{~nm})$ associated rehabilitation protocol for 12 weeks, with two weekly sessions and at least $48 \mathrm{~h}$ between sessions.

Rehabilitation protocol associated with laser photobiomodulation $(830 \mathrm{~nm})$ : participants in this group will receive treatment through the laser photobiomodulation $(830 \mathrm{~nm})$ associated rehabilitation protocol for 12 weeks, with two weekly sessions and at least $48 \mathrm{~h}$ between sessions.

The laser photobiomodulation will be applied to the articular line radiating four points in each session, with energy density of $6 \mathrm{~J}$ per point, continuous wave and wavelength of $660 \mathrm{~nm}$ and $830 \mathrm{~nm}$, the energy was based on the study of Youssef et al. [20].

The exercise protocol was describe in stages (Table 1): Stage 1 - (1PO up to 7 days): Active movement of the lower limbs gradually increasing the degrees of amplitude, patellar mobilization, stretching of the hamstrings, gastrocnemius, soleus, quadriceps and hip muscles, strengthening with isometric quadriceps and hamstrings, extended leg lifting exercises for flexion, extension, hip abduction and abduction, weight bearing with bipodal support according to medical guidance, scar management, guidelines for home exercises and guidelines and training for reeducation of gait; Stage 2 - (2nd week to $4^{\text {th }}$ week): Maintaining initial behavior and with improvement of painful condition initiates isotonic strengthening of the knee flexor and extensor muscles, hip abductors and adductors and CORE muscles, beginning of sensory motor training with unipodal balance on stable surface evolving to unstable, mini-gait exercises and anteroposterior and lateral gait training; Stage 3 - (5th week to 8th week): Maintain stretches, increase load for strengthening exercises, perform unipodal squatting exercises, make sensorimotor exercises difficult, anterior and posterior trot; Stage 4 - (9th week until the 12th week): Maintain stretching, maintain muscle strengthening of the lower limbs and CORE with increased load, high complexity sensorimotor exercise, exercise training and jumps, sports and or occupational gesture training.

\section{Results}

Two individuals participated in the study, and until the moment one completed the treatment, and one gave up treatment. The participant who completed the protocol is female, aged 51 years, and the affected knee being the right. Patient received the treatment protocol associated with laser photobiomodulation Laser $(830 \mathrm{~nm})$. The results of the pre and post treatment evaluation are described and expressed in the tables below.

The results of the questionnaires (Table 2) showed an improvement when compared before and after the treatment protocol. The SF-12 questionnaire showed an improvement of 15 points. The IPAQ short
Table 1. Protocol of the rehabilitation after partial meniscectomy

\begin{tabular}{|c|c|c|}
\hline \multicolumn{3}{|c|}{ Stage 1: $1^{\text {st }}$ Post-operative (PO) up to 7 days PO } \\
\hline $1^{\text {st }} \mathbf{P O}$ & Orientation & $\begin{array}{l}\text { - Knee positioning (do not put pillow under knee); } \\
\text { - Metabolic Exercises }\end{array}$ \\
\hline \multirow{6}{*}{$\begin{array}{l}\text { 2nd PO up to } \\
\text { 7th day PO }\end{array}$} & ROMA & $\begin{array}{l}\text { - Active movement of lower limbs; } \\
\text { - Gain of the ROM lower limb affected pain free. }\end{array}$ \\
\hline & Strength & $\begin{array}{l}\text { - Isometric exercises for lower limb musculature; } \\
\text { - Evolving to Straight Leg Raise (SLR) }\end{array}$ \\
\hline & $\begin{array}{l}\text { Weight } \\
\text { discharge }\end{array}$ & $\begin{array}{l}\text { - Controlled Weight Discharge } \\
\text { - Partial load as tolerated by the patient }\end{array}$ \\
\hline & Edema & - Edema control with affected limb elevation \\
\hline & Scar & - Scar management \\
\hline & Gait & - Gait Training with assistance device \\
\hline
\end{tabular}

Stage 2: 8th day until 4th Week

\begin{tabular}{|c|c|c|}
\hline \multirow{7}{*}{$\begin{array}{l}\text { 2nd until 4th } \\
\text { Week }\end{array}$} & ROMA & $\begin{array}{l}\text { - Active movement of lower limbs; } \\
\text { - Gain of the ROM lower limb affected pain free; }\end{array}$ \\
\hline & Strength & $\begin{array}{l}\text { - Isotonic exercise of the knee flexor and extensor } \\
\text { muscles; } \\
\text { - Hip abductors and adductors; } \\
\text { - Exercise for CORE muscles. } \\
\text { - Mini Squat Exercises }\end{array}$ \\
\hline & $\begin{array}{l}\text { Weight } \\
\text { discharge }\end{array}$ & $\begin{array}{l}\text { - Controlled Weight Discharge } \\
\text { - Partial load as tolerated by the patient }\end{array}$ \\
\hline & Edema & - Edema control with affected limb elevation \\
\hline & Scar & - Scar management \\
\hline & Gait & $\begin{array}{l}\text { - Gait training } \\
\text { - Anteroposterior } \\
\text { - Lateral }\end{array}$ \\
\hline & $\begin{array}{l}\text { Sensory motor } \\
\text { training }\end{array}$ & $\begin{array}{l}\text { - Bipodal for Unipodal balance training on stable } \\
\text { surface evolving to unstable; }\end{array}$ \\
\hline \multicolumn{3}{|c|}{ Stage 3: 5th Week to 8th Week } \\
\hline \multirow{5}{*}{$\begin{array}{l}\text { 5th until 8th } \\
\text { Week }\end{array}$} & ROMA & $\begin{array}{l}\text { - Active movement of lower limbs; } \\
\text { - Gain of the ROM lower limb affected pain free (if } \\
\text { necessary) }\end{array}$ \\
\hline & strengthening & $\begin{array}{l}\text { - Increased loading } \\
\text { - Isotonic exercise of the knee flexor and extensor } \\
\text { muscles; } \\
\text { - Hip abductors and adductors; } \\
\text { - CORE muscles } \\
\text { - Single-legged squatting exercises }\end{array}$ \\
\hline & Scar & - Scar management (if necessary) \\
\hline & Gait & - Anterior and posterior trot \\
\hline & $\begin{array}{l}\text { Sensory motor } \\
\text { training }\end{array}$ & $\begin{array}{l}\text { - Bipodal or Unipodal balance training on unstable } \\
\text { surface; associate the task double }\end{array}$ \\
\hline \multicolumn{3}{|c|}{ Stage 4: $9^{\text {th }}$ Week until 12th Week } \\
\hline \multirow{6}{*}{$\begin{array}{l}\text { 9th until 12th } \\
\text { Week }\end{array}$} & strengthening & $\begin{array}{l}\text { - Increased loading } \\
\text { - Isotonic exercise of the knee flexor and extensor } \\
\text { muscles; } \\
\text { - Hip abductors and adductors; } \\
\text { - CORE muscles } \\
\text { - Single-legged squatting exercises }\end{array}$ \\
\hline & Gait & - Running and jumping training \\
\hline & $\begin{array}{l}\text { Sensory motor } \\
\text { training }\end{array}$ & $\begin{array}{l}\text { - Unipodal balance training on unstable surface; whit } \\
\text { task double associate upper limb }\end{array}$ \\
\hline & \multicolumn{2}{|c|}{ Sport and / or occupational gesture training } \\
\hline & \multicolumn{2}{|c|}{ Plyometric Training (according to the patients' need) } \\
\hline & \multicolumn{2}{|c|}{ Discharge from physiotherapeutic treatment } \\
\hline
\end{tabular}

Table 2. Results of the questionnaires in before and after treatment of the volunteer

\begin{tabular}{|c|c|c|}
\hline Questionnaire & Before treatment & Post treatment \\
\hline SF-12 & 22 & 37 \\
\hline IPAQ & Non Active & Active \\
\hline Lysholm & 17 (poor) & 91 (good) \\
\hline Womac Index & 85,41 & 5,40 \\
\hline
\end{tabular}

version also demonstrates improvement, which is justified because initially it can not perform physical activity, and after the treatment returns to usual activities. The Lysholm questionnaire represents a 
large difference in their values before and after treatment, and before treatment their symptoms in the knee were classified as bad, and after as good. Already the Womac index that represents its score the worse the worse the health condition, had an improvement of 80.1 points.

Surface electromyography, as shown in table 3, showed a increase in muscle activation (RMS) of amost all evaluated muscles, rectus femoris, vastus lateralis, biceps femoris and semitendinosus, except the semitendinous and biceps femoris muscles in the left lower limb. In the evaluation of the Fmed, was observed in low limb affected a decrease of the Fmed and in limb non-affected a increaseof the vastus lateralis and semitendinous.

Checking the perimetry values (Table 4 ), we can analyze the comparison between the two lower limbs, and confirmed the presence of edema in the right lower limb, and that this reduces when analyzed the data after treatment. Table 5 shows the results obtained with goniometry, demonstrating a reduction in the range of motion in the left lower limb in all movements, knee flexion and extension, and medial and lateral hip rotation and showing a $20^{\circ}$ improvement in flexion and knee extension, $15^{\circ}$ increase in medial rotation and $10^{\circ}$ and lateral rotation of the affected knee (right) in the post treatment. When we analyzed the values of maximum isometric muscle strength (Table 6), we noticed a great gain of muscle strength of knee extensors $(8 \mathrm{~kg})$; Rotators lateral (9 kg); Average rotors (12.2 kg); knee flexors (11.8 kg) in lower right limb. In addition, the protocol also provided a trend in increased muscle strength of the contralateral lower limb.

Finally, the table 7 expresses the data of the other tests performed. Since the Hop test the patient could not perform, and the $\mathrm{Y}$ balance test was performed only at the end of the treatment, not presenting data for a pre and post treatment comparison. The right and left lateral

Table 3. Data before and after treatment of the surface electromyography, the data are described in root mean square (RMS) and median frequency (Fmed)

\begin{tabular}{|c|c|c|c|c|}
\hline \multirow{2}{*}{ Muscles } & \multicolumn{2}{|c|}{ Before } & \multicolumn{2}{c|}{ After } \\
\cline { 2 - 5 } & RMS & Fmed & RMS & Fmed \\
\hline Rectus femoris R & 24,84 & 126,04 & 38,39 & 118,24 \\
\hline Vastus lateralis R & 58,53 & 121,82 & 77,02 & 119,05 \\
\hline Biceps femoris R & 14,18 & 120,85 & 21,65 & 112,71 \\
\hline Semitendinous R & 39,77 & 93,67 & 59,07 & 94,56 \\
\hline Rectus femoris L & 29,98 & 123,53 & 46,13 & 124,18 \\
\hline Vastus lateralis L & 67,19 & 120,28 & 80,66 & 135,90 \\
\hline Biceps femoris L & 35,67 & 115,96 & 31,43 & 115,39 \\
\hline Semitendinous L & 124,86 & 99,28 & 69,77 & 110,67 \\
\hline
\end{tabular}

Table 4. Results of the perimetry at evaluation before and after treatment

\begin{tabular}{|c|c|c|c|c|c|}
\hline \multicolumn{7}{|c|}{ Perimetry Low Limb Right } \\
\hline $\begin{array}{c}\text { Upper edge } \\
\text { of the patella }\end{array}$ & $\begin{array}{c}\text { Before } \\
\text { treatment }\end{array}$ & $\begin{array}{c}\text { Post } \\
\text { treatment }\end{array}$ & $\begin{array}{c}\text { Low edge of } \\
\text { the patella }\end{array}$ & $\begin{array}{c}\text { Before } \\
\text { treatment }\end{array}$ & $\begin{array}{c}\text { Post } \\
\text { treatment }\end{array}$ \\
\hline $5 \mathrm{~cm}$ & 51,5 & 48 & $5 \mathrm{~cm}$ & 40 & 40,5 \\
\hline $10 \mathrm{~cm}$ & 56,5 & 54 & $10 \mathrm{~cm}$ & 40 & 40,5 \\
\hline $15 \mathrm{~cm}$ & 66 & 64 & $15 \mathrm{~cm}$ & 37,5 & 38,5 \\
\hline $20 \mathrm{~cm}$ & 70,5 & 70 & & & \\
\hline & \multicolumn{5}{|c|}{ Perimetry Low Limb Left } \\
\hline & Thigh & & & Leg & \\
\hline $\begin{array}{c}\text { Upper edge } \\
\text { of the patella }\end{array}$ & $\begin{array}{c}\text { Before } \\
\text { treatment }\end{array}$ & $\begin{array}{c}\text { Post } \\
\text { treatment }\end{array}$ & $\begin{array}{c}\text { Low edge of } \\
\text { the patella }\end{array}$ & $\begin{array}{c}\text { Before } \\
\text { treatment }\end{array}$ & $\begin{array}{c}\text { Post } \\
\text { treatment }\end{array}$ \\
\hline $5 \mathrm{~cm}$ & 48,5 & 51 & $5 \mathrm{~cm}$ & 39,5 & 40 \\
\hline $10 \mathrm{~cm}$ & 55,5 & 56 & $10 \mathrm{~cm}$ & 40 & 41 \\
\hline $15 \mathrm{~cm}$ & 66,5 & 66,5 & $15 \mathrm{~cm}$ & 38,5 & 39 \\
\hline $20 \mathrm{~cm}$ & 72 & 72 & & & \\
\hline
\end{tabular}

Table 5. Results of the Range of motion $\left(^{\circ}\right)$ in evaluation before and after treatment

\begin{tabular}{|l|c|c|c|c|}
\hline \multirow{2}{*}{ Range of motion } & \multicolumn{2}{|c|}{ Before } & \multicolumn{2}{c|}{ After } \\
\cline { 2 - 5 } & Right & Left & Right & Left \\
\hline Active knee Flexion & $110^{\circ}$ & $130^{\circ}$ & $130^{\circ}$ & $130^{\circ}$ \\
\hline Passive Knee Flexion & $120^{\circ}$ & $140^{\circ}$ & $140^{\circ}$ & $140^{\circ}$ \\
\hline Active knee Extension & $100^{\circ}$ & $130^{\circ}$ & $120^{\circ}$ & $130^{\circ}$ \\
\hline Passive Knee Extension & $110^{\circ}$ & $130^{\circ}$ & $130^{\circ}$ & $140^{\circ}$ \\
\hline Active Hip Medial Rotation & $30^{\circ}$ & $35^{\circ}$ & $45^{\circ}$ & $45^{\circ}$ \\
\hline Passive Hip Medial Rotation & $35^{\circ}$ & $45^{\circ}$ & $45^{\circ}$ & $45^{\circ}$ \\
\hline Active Hip Lateral Rotation & $30^{\circ}$ & $35^{\circ}$ & $40^{\circ}$ & $40^{\circ}$ \\
\hline Passive Hip Lateral Rotation & $35^{\circ}$ & $45^{\circ}$ & $45^{\circ}$ & $45^{\circ}$ \\
\hline
\end{tabular}

Table 6. Results of the maximum isometric muscle strength test in evaluation before and after treatment

\begin{tabular}{|c|c|c|c|c|c|c|c|c|}
\hline $\begin{array}{c}\text { Muscular } \\
\text { groups }\end{array}$ & \multicolumn{2}{|c|}{ Knee Extensors } & \multicolumn{2}{c|}{$\begin{array}{c}\text { Laterals } \\
\text { Rotation }\end{array}$} & \multicolumn{2}{c|}{$\begin{array}{c}\text { Medials } \\
\text { Rotation }\end{array}$} & \multicolumn{2}{c|}{$\begin{array}{c}\text { Hip Extensors } \\
\text { and Knee flexors }\end{array}$} \\
\hline & Before & Post & Before & Post & Before & Post & Before & Post \\
\hline Right & 6,7 & 14,7 & 4 & 13 & 3 & 15,2 & 2,7 & 12,1 \\
\hline Left & 17,6 & 25 & 11,2 & 15 & 7,1 & 36,5 & 15,7 & 13,9 \\
\hline
\end{tabular}

Table 7. Results of the evaluation of the pain and functional tests before and after treatment

\begin{tabular}{|c|c|c|}
\hline Tests & Before & After \\
\hline Lateral planks right & 0 seconds & 07 seconds \\
\hline Lateral planks left & 06 seconds & 13 seconds \\
\hline TUG & 14 seconds & 08 seconds \\
\hline VAS & 7 & 0 \\
\hline Hop Test & Non evaluation & Non evaluation \\
\hline Y Balance Test right & Non evaluation & 82,15 \\
\hline Y Balance Test left & Non evaluation & 79,27 \\
\hline
\end{tabular}

TUG: Timed Get Up and Go; VAS: Visual Analoic Scale.

planks showed an increase of 07 seconds when compared to pre and post treatment.

The performance of the Timed Get Up and Go showing a reduction of the time of 06 seconds, and the visual analogue scale of the pain also presented a great improvement, being that in the beginning the patient reported a pain 07 of 10 , and in the end she was absent of pain.

\section{Discussion}

The objective of this study is to compare the influence of a rehabilitation protocol associated with laser photobiomodulation (660 $\mathrm{nm}$ and $830 \mathrm{~nm}$ ), observing the function, muscular strength, activation and firing rate of limbs lower in post-surgical patients with partial meniscectomy, and reassessed volunteers at a follow-up of 30 days and 90 days after the end of the rehabilitation protocol. There are several studies that evaluate individuals after meniscal lesions, the purpose and the differential of this protocol will be to provide an early approach to patients who undergo partial meniscectomy, post degenerative injury or trauma.

The use of laser photobiomodulation was based on several experimental and clinical studies demonstrating the effectiveness of this electrophysical agent in musculoskeletal injuries [21-26]. There are several possible explanations for the positive effects of this treatment. The authors believe that an increase in the pain threshold $[27,28]$, its action on cannabinoid receptors to modulate pain [29], Improved blood flow and regeneration of the knee cartilage are the main contributors $[30,31]$. in addition, it has been recommended for its effects on the modulation of the inflammatory process $[32,33]$ and its efficacy in healing $[34,35]$.

The reduction of pain obtained by laser photobiomodulation can be explained by the increase in levels of neurotransmitters, 
including serotonin, which is important in the modulation of endogenous pain [36]. Several studies have reported positive effects of laser photobiomodulation, including influences on fibroblast propagation, osteoblasts production and collagen synthesis, as well as revascularization in wound healing [37]. In addition, it has a positive effect on the modulation of inflammation $[32,33,38]$ and stimulation of angiogenesis, as well as in the reduction of fibrosis formation [34]. Improvements in physical joint function results usually occur as a consequence of reduced pain intensity, since pain reduction is usually primarily responsible for improvements in muscle function [39].

Youssef et al. [20] treated 60 patients with knee osteoarthritis (OA) who were divided into 3 groups, two active laser groups and one placebo receiving 16 physiotherapy sessions twice a week. The active laser group, both $6 \mathrm{~J} / \mathrm{cm}^{2}$ and $3 \mathrm{~J} / \mathrm{cm}^{2}$, had a significant reduction in pain intensity in VAS and WOMAC, increased physical function, increased isometric quadriceps and hamstring strength, and increased range of motion after knee OA treatment. Regarding the dose of laser applied, in this study, the authors found that the application of $6 \mathrm{~J} / \mathrm{cm}^{2}$ was more effective than $3 \mathrm{~J} / \mathrm{cm}^{2}$ during the treatment of patients with OA knee.

The initial objectives of physiotherapy after partial meniscectomy are: pain control and edema, maximal knee amplitude and walking at full load. There is no load limitation, this is compatible with patient tolerance [1]. The rehabilitation treatment starts from the first postoperative day with pharmacological pain control, swelling resolution and individual exercise programs, to restore, as soon as possible and with care, knee joint mobility, muscular forces and physiological gait $[2,40]$.

Logerstedt et al. [41] stresses that isometric contraction exercises of the quadriceps should be started immediately after surgery, but only after the third to fifth week (depending on the type of meniscal damage) more complex muscular strengthening exercises such as the minisquatting are performed. Between the third and fifth postoperative weeks, the patient initiates proprioceptive and balance exercises, even when the load is partial, while only from the fifth to the seventh week it is possible to perform these exercises at full load [2,41]. Return to complete physical activity is possible six to eight weeks after partial meniscectomy [2]. The present study proposes an earlier approach, initiating rehabilitation on the first day after surgery, in order to do stretching to gain range of motion, weight release and initiate laser performance as a way to accelerate the healing process. In this way progressing the loads and the difficulty of the exercises, going from isometric to isotonic strengthening.

The study presented important limitations regarding population and sample. There was difficulty in the adherence of these patients, as the presence on the days of treatment, for the protocol to be performed as predicted. In addition, the immediate postoperative care of these patients did not occur, or they did not reach our laboratory, with little adherence to the treatment.

The analysis of several rehabilitation protocols used in different studies has been limited because many do not report in detail the type of rehabilitation program, nor even the best alternative of the parameters of laser photobiomodulation. As reported by the recent guidelines of Logerstedt et al. [41], there is a lack of scientific evidence on the effectiveness of rehabilitation protocols and further studies are needed. With this, we bring to the scientific community a protocol with an early approach and the care with follow-up during the treatment until the follow up of 30 and 90 days after the end of the protocol, and we suggest new researches with this protocol mainly with a larger sample number.

\section{Conclusion}

This treatment protocol proved to be adequate and effective for the post-operative meniscectomy patient, offering benefits in terms of pain reduction and improvement in function. The findings of this case study are expected to contribute to the body of evidence-based practice available to clinicians in order to provide effective management of partial meniscectomy.

\section{Conflict of interest}

The authors declare that they have no conflict of interest.

\section{References}

1. Brindle T, Nyland J, Johnson DL (2001) The meniscus: review of basic principles with application to surgery and rehabilitation. J Athl Train 36: 160-169. [Crossref]

2. Heckmann TP, Barber-Westin SD, Noyes FR (2006) Meniscal repair and transplantation: indications, techniques, rehabilitation, and clinical outcome. J Orthop Sports Phys Ther 36: 795-814. [Crossref]

3. Mordecai SC, Al-Hadithy N, Ware HE, Gupte CM (2014) Treatment of meniscal tears An evidence based approach. World J Orthop 5: 233-241. [Crossref]

4. Frizziero A, Ferrari R, Giannotti E, Ferroni C, Poli P, et al. (2013) The meniscus tear State of the art of rehabilitation protocols related to surgical procedures. Muscles Ligaments Tendons $J$ 2: 295-301. [Crossref]

5. Brelin AM, Rue JP (2016) Return to Play Following Meniscus Surgery. Clin Sports Med 35: 669-678. [Crossref]

6. Nakamura T, Ebihara S, Ohkuni I, Izukura H, Harada T, et al. (2014) Low Level Laser Therapy for chronic knee joint pain patients. Laser Ther 23: 273-277. [Crossref]

7. Benedetti TRB, Priscilla de Cesaro Antunes, Ciro Romélio Rodriguez-Añez, Giovana Zarpellon Mazo, Édio Luiz Petrosk, (2007) Reprodutibilidade e validade do Questionário Internacional de Atividade Física (IPAQ) em homens idosos. Rev Bras Med Esporte 13:11-16.

8. Metsavaht L, Gustavo Leporace, Maria Matilde de Mello Sposito, Marcelo Riberto, Luiz Alberto Batista, (2011) Qual o melhor questionário para avaliar os aspectos físicos de pacientes com osteoartrite no joelho na população brasileira? Rev Bras Ortop 46: 256-261.

9. Peccin MS, Ciconelli R, Cohen M (2006) Questionário específico para sintomas do joelho "Lysholm Knee Scoring Scale": tradução e validação para a língua portuguesa. Acta Ortop Bras 14: 268-272.

10. Mutlu EK, Ozdincler AR (2015) Reliability and responsiveness of algometry for measuring pressure pain threshold in patients with knee osteoarthritis. J Phys Ther Sci 27: 1961-1965. [Crossref]

11. Pelfort X, Torres-Claramunt R, Sánchez-Soler JF, Hinarejos P, Leal-Blanquet J, et al. (2015) Pressure algometry is a useful tool to quantify pain in the medial part of the knee: An intra- and inter-reliability study in healthy subjects. Orthop Traumatol Surg Res. 101: 559-563. [Crossref]

12. Magee, DJ (2010) Musculoskeletal Evaluation $5^{\text {th }}$ Edition.

13. Mcgill SM, Childs A, Liebenson C (1999) Endurance times for stabilization exercises: clinical targets for testing and training from a normal database. Arch Phys Med Rehabil. 80: 941-944. [Crossref]

14. Liebenson C (2004) Spinal stabilization - an update: Part 2 - Functional assessment. $J$ Bodyw Mov Ther 8: 199-210.

15. Stiffler MR, Sanfilippo JL, Brooks MA, Heiderscheit BC (2015) Star Excursion Balance Test Performance Varies by Sport in Healthy Division I Collegiate Athletes. $J$ Orthop Sports Phys Ther 45: 772-780. [Crossref]

16. Chimera, NJ, Kremer K (2016) Sportsmetrics training improves power and landing in High School rowers. Int J Sports Phys Ther 11: 44-54. [Crossref]

17. Butowicz CM, Ebaugh DD, Noehren B, Silfies SP (2016) Validation of two clinical measures of core stability. Int J Sports Phys Ther 11: 15-24. [Crossref]

18. Alnahdi AH, Alderaa AA, Aldali AZ, Alsobayel H, (2015) Reference values for the $\mathrm{Y}$ Balance Test and the lower extremity functional scale in young healthy adults. $J$ Phys Ther Sci 27: 3917-3921. [Crossref]

19. Hermens HJ, Freriks B, Disselhorst-Klug C, Rau G (2000) Development of recommendations for SEMG sensors and sensor placement procedures. J Electromyogr Kinesiol 10: 361-374. [Crossref] 
20. Youssef EF, Muaidi QI, Shanb AA (2016) Effect of Laser Therapy on Chronic Osteoarthritis of the Knee in Older Subjects. J Lasers Med Sci 7: 112-119. [Crossref]

21. Maegawa Y, Itoh T, Hosokawa T, Yaegashi K, Nishi M (2000) Effects of nearinfrared low-level laser irradiation on microcirculation. Lasers Surg Med 27: 427-437. [Crossref]

22. Pham M, Hull ML (2007) Dehydration rates of meniscus and articular cartilage in vitro using a fast and accurate laser-based coordinate digitizing system. J Biomech 40: 3223 3229. [Crossref]

23. Raunest J, Derra E (1995) Morphological, biomechanical and experimental in vivo studies of laserassisted meniscus resection. Langenbecks arch chir 380: 12-21. [Crossref]

24. Horan PJ, Popovic NA, Islinger RB, Kuklo TR, Dick EJ Jr, et al. (1999) Acute and long-term response of the meniscus to partial meniscectomy using the holmium: YAG laser. Arthroscopy 15: 155-164. [Crossref]

25. Atik OS, Erdogan D, Omeroglu S, Tali T, Korkusuz F, et al. (2001) Histological and magnetic resonance imaging alterations after irradiation of meniscus using Holmium: YAG laser. J Clin Laser Med Surg 19: 245-250. [Crossref]

26. Harada T, Ohkuni I, Tsuruoka HA (1998) Clinical Application of the $1 \mathrm{~W}$ Ga-Al-As diode laser: Double Blind Study. J Physical Medicine 9: 99-103.

27. Gottlieba T, et al (2006) The influence of irradiation with low-level diode laser on the proteoglycan content in arthritically changed cartilage in rabbits. Med Laser Appl 21: 53-59.

28. Rayegani SM, Bahrami MH, Elyaspour D, Saeidi M, Sanjar H (2012) Therapeutic effects of low level laser therapy (LLLT) in knee osteoarthritis, compared to therapeutic ultrasound. J Lasers Med Sci 3: 71-74.

29. Neves LMS, Gonçalves ECD, Cavalli J, Vieira G, Laurindo LR, et al. (2018) Photobiomodulation Therapy Improves Acute Inflammatory Response in Mice: the Role of Cannabinoid Receptors/ATP-Sensitive K+ Channel/p38-MAPK Signalling Pathway. Mol Neurobiol 55: 5580-5593. [Crossref]

30. Pollo FE, Jackson RW, Kane RR, Chang HM, Zhang J, et al. (2004) Dieterichs CP, Riedel S. Sutureless avascular meniscal repair with a photoactive naphthalimide compound: a preliminary animal study. Arthroscopy 20: 824-830. [Crossref]
31. Vangsness CT Jr, Akl Y, Marshall GJ, Subin W, Smith CF (1994) The effects of the neodymium laser on meniscal repair in the avascular zone of the meniscus. Arthroscopy 10: 201-205. [Crossref]

32. Alves AC, Vieira R, Leal-Junior E, dos Santos S, Ligeiro AP, et al. (2013) Effect of lowlevel laser therapy on the expression of inflammatory mediators and on neutrophils and macrophages in acute joint inflammation. Arthritis Res Ther 15: R116. [Crossref]

33. Castano AP, Dai T, Yaroslavsky I, Cohen R, Apruzzese WA, et al. (2007) Low-level laser therapy for zymosan-induced arthritis in rats: Importance of illumination time. Lasers Surg Med 39: 543-550. [Crossref]

34. da Rosa AS, dos Santos AF, da Silva MM, Facco GG, Perreira DM, et al. (2012) Effects of low-level laser therapy at wavelengths of 660 and $808 \mathrm{~nm}$ in experimental model of osteoarthritis. Photochem Photobiol 88: 161-166. [Crossref]

35. Chen D (2007) Updated therapy in elderly patients with Knee osteoarthritis. Int $J$ Gerontol 1: 31-39.

36. Brosseau L, Milne S, Robinson V, Marchand S, Shea B, et al. (2002) Efficacy of the transcutaneous electrical nerve stimulation for the treatment of chronic low back pain: a meta-analysis. Spine 27: 596-603. [Crossref]

37. Adams T, Band-Entrup D, Kuhn S, Legere L, Mace K, et al. (2013) Physical therapy management of knee osteoarthritis in the middle-aged athlete. Sports Med Arthrosc 21: 2-10. [Crossref]

38. Marovino T (2004) Cold lasers in low-level laser therapy pain management. Practical Pain Management 4:

39. Hassan BS, Doherty SA, Mockett S, Doherty M (2002) Effect of pain reduction on postural sway, proprioception, and quadriceps strength in subjects with knee osteoarthritis. Ann Rheum Dis 61: 422-428. [Crossref]

40. Noyes FR, Berrios-Torres S, Barber-Westin SD, Heckmann TP (2000) Prevention of permanent arthrofibrosis after anterior cruciate ligament reconstruction alone or combined with associated procedures: a prospective study in 443 knees. Knee Surg Sports Traumatol Arthrosc 8: 196-206. [Crossref]

41. Logerstedt DS, Snyder-Mackler L, Ritter RC, Axe MJ (2010) Knee pain and mobility impairments: meniscal and articular cartilage lesions. J Orthop Sports Phys Ther 40 : A1-A35. [Crossref]

Copyright: (C2019 Junglos VC. This is an open-access article distributed under the terms of the Creative Commons Attribution License, which permits unrestricted use, distribution, and reproduction in any medium, provided the original author and source are credited. 